\title{
Exploring the required success factors for developing absorptive capacity in knowledge intensive organisations
}

\author{
Muhammad Rafique \\ College of Electrical and Mechanical Engineering, National University of Science and Technology \\ Peshawar Road, Rawalpindi, Pakistan \\ E-mail: raf.sibi@ceme.nust.edu.pk \\ Richard David Evans \\ Business Information Management and Operations, University of Westminster \\ London NW1 5LS, United Kingdom \\ Muhammad Tahir Nawaz \\ College of Electrical and Mechanical Engineering, National University of Science and Technology \\ Peshawar Road, Rawalpindi, Pakistan \\ Mujtaba Agha \\ Mechanical Engineering, Mohammad Ali Jinnah University \\ Islamabad Expressway, Kahuta Road, Zone-V, Pakistan
}

\begin{abstract}
Absorptive capacity is a developing research topic within the field of knowledge management, whereby researchers are exploring business methods for improving the capture and valuation of new knowledge entering organisations from external sources. Organisational processes and human-centred systems at macro-level, in relation to absorptive capacity, have been explored extensively but typically in a generalised form. Antecedents highlighting the successful implementation of absorptive capacity processes have not been intensely studied to date. This study, through critical exploration of existing success factors within pharmaceutical organisations based in Pakistan, aims to extend this body of knowledge by highlighting the requirements required for the effective development of absorptive capacity in the workplace. Results show that factors relating to employees and management, both at mid and senior level, are critical in the successful development of absorptive capacity. Furthermore, this study explores new pathways for critical evaluation of absorptive capacity in relation to employees and management.
\end{abstract}

Keywords: Absorptive Capacity, Case Study, Knowledge Intensive Organisations, Knowledge Management.

\section{Introduction}

Employee knowledge is recognised ${ }^{1,2}$ as one of the most valuable and important components owned by an organisation today. In order to survive and maintain competitive advantage, companies operating in knowledge intensive environments, such as the global pharmaceutical sector, are now required to make greater use of what their employees already know. ${ }^{3,4}$ Sources of organisational knowledge may originate from two broad categories: 1) generation of knowledge from within the organisation (tacit or explicit), and 2) knowledge from outside the organisation (typically explicit and found in extended supply chains). Companies require specific capabilities to deal with this external knowledge, including successful Absorptive Capacity (AC). ${ }^{5}$

During the last three decades, the field of Knowledge Management (KM) has evolved into its own research domain, with organisations and academic institutions alike now striving to gain a competitive 
edge in ever-changing technological environments. ${ }^{6}$ Knowledge from outside of an organisation has subsequently grown in importance and firms who possess effective knowledge processing capabilities may now enhance their knowledge memories, according to Ref. 1; it is, therefore, important for organisations to enhance these capabilities to deal with new knowledge from external sources.

The purpose of this paper is to extend the literature currently-available on absorptive capacity published in the International Technology Management Review, by exploring the critical success factors which play a crucial role in the development of $\mathrm{AC}$ from a $\mathrm{KM}$ perspective.

It is often found that factors relate to mid and senior level management and employees, which directly affects absorptive capacity and factors relating to it; antecedents, however, related to procedure-related factors which directly affect the absorptive capacity process, are yet to be fully explored.

\section{Literature Review}

In order to gain a greater appreciation for recent research conducted into the field of absorptive capacity, a keyword-based review of published research from 2005-2015 was conducted using Elsevier's academic database, Scopus. In total, 1,045 unique papers were identified using the keyword of 'absorptive capacity'. The most popular keywords used in conjunction with 'absorptive capacity' were 'Innovation' (232), 'Knowledge Management' (181) 'Industry' (175) and 'Competition' (81). It could be hypothesised, through analysis of these keywords, that researchers typically associate new knowledge gathered from external sources as an innovative process which requires a level of creativity and openness on behalf of organisations to allow knowledge into their companies. It could also be hypothesized that an organisation's ability to develop absorptive capacity will assist in its ability to compete in the market; in future, these hypotheses could be researched in their own right, but for the purpose of this paper it will not be explored further.

From the identified 1045 publications, 641 were published as journal articles, 336 as conference papers, 32 as press articles, 28 as review papers and 8 as book chapters. Journals featuring work related to absorptive capacity included: Elsevier's Research Policy Journal
(33), the Strategic Management Journal (19), Technovation (18) and the International Business Review (18) inter alia. As can be seen in Fig.1., the majority of recent research relating to absorptive capacity was conducted between the years of 2010-2014 $(70.0 \%)$.

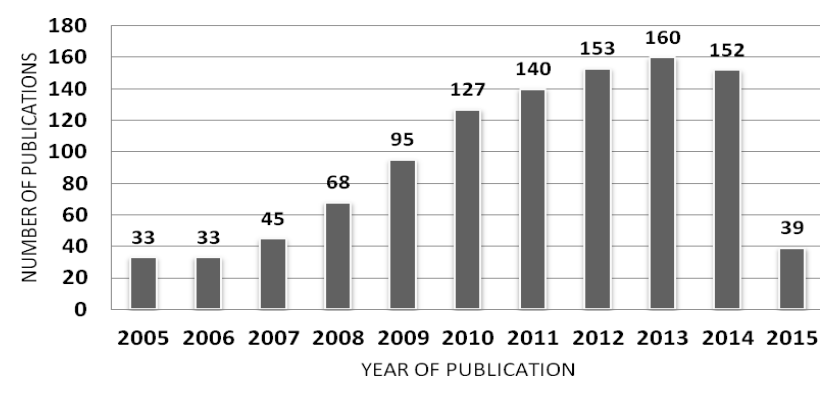

Fig. 1. Number of Publications by Year.

The greatest number of publications on the topic of absorptive capacity emanate from the United States (211), while authors in China published 199 articles and in the United Kingdom, 100 articles; other key contributors by country included: Spain (73), Germany (60) and Australia (49). In terms of the affiliation in which papers were published, Zhejiang University, China, published 21 individual papers, while Harbin Institute of Technology, China, published 13 and Lappeenrannan Teknillinen Yliopisto (Finland) and Imperial College London (UK) published 11 papers each.

With regard to those papers published in the International Technology Management Review, no articles were found specifically exploring the absorptive capacity of organisations. However, research was deduced which explored knowledge management from various perspectives, including education ${ }^{7}$, design of models or systems ${ }^{8,9}$ and employee practices ${ }^{10}$.

\subsection{The Evolution of Absorptive Capacity}

Absorptive capacity was first introduced by Ref. 5 in 1990 who defined it as the capability of an organisation to deal with new knowledge obtained from outside of the organisation, as illustrated in Fig.2. For the purpose of this research, we add that for successful absorptive capacity, organisations must be able to recognise and deal with this new valuable knowledge and define it as the intelligence of a company to recognise the value in new external knowledge entering the company, assimilate it and apply it into an organisation practices. 
The three components, shown in Fig. 3, were defined by Ref. 11 who introduced four components of absorptive capacity, namely acquisition and assimilation which referred to potential absorptive capacity and transformation and exploitation of knowledge, which is referred to as 'realised absorptive capacity'.

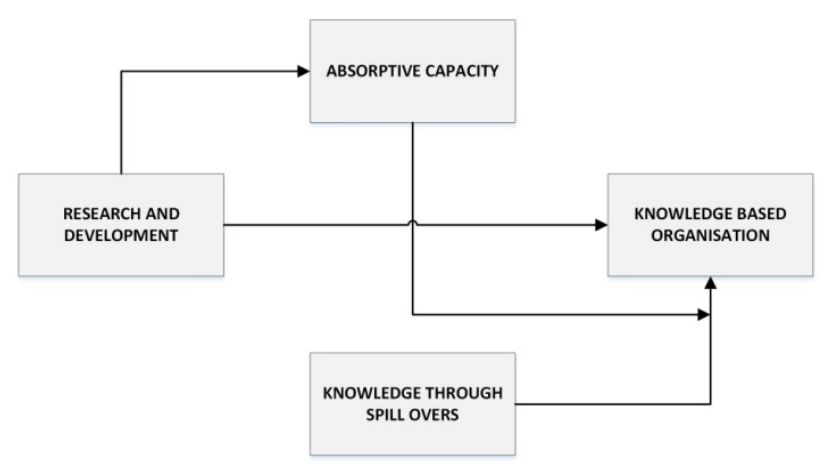

Fig. 2. New knowledge Path of an Organisation, adapted from Ref. 5.

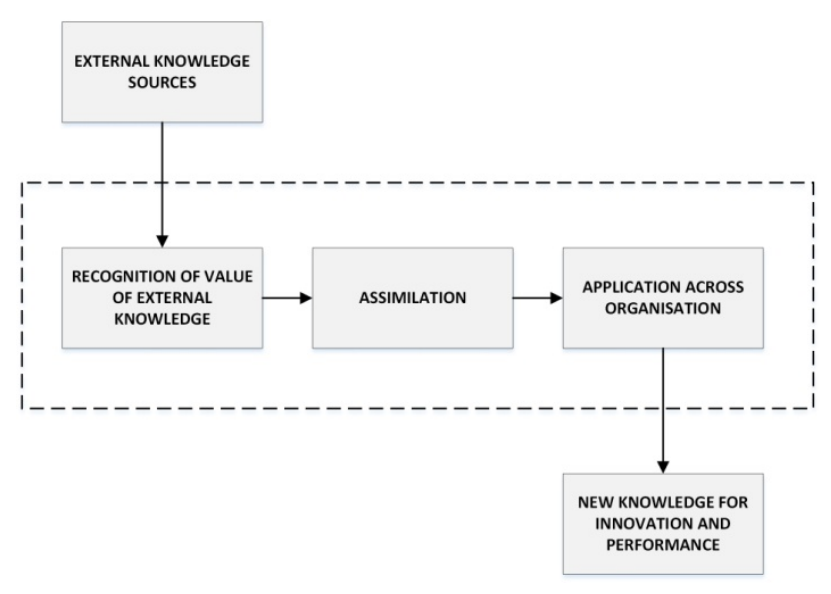

Fig. 3. Three Components of Absorptive Capacity, adapted from Ref. 5.

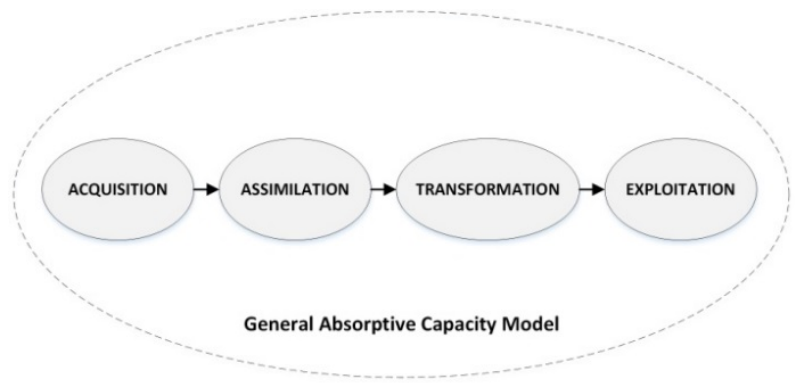

Fig. 4. General absorptive capacity model, adapted from Ref. 11.
These three components have been discussed in different dimensions in relation to knowledge processing activities and Fig.4. shows the absorptive capacity process often found in literature in a generalised form.

Absorptive capacity has been discussed from different perspectives in recent times, with the above construct evolving following its introduction. The development of absorptive capacity has been viewed by incorporating different antecedents both inside and outside of the organisation, as suggested by Ref. 12 and 13 , who suggested that antecedents should be applied within an organisation for the development of absorptive capacity. Ref. 14 and 15 focused on antecedents external to an organisation, while Ref. 16 focused more on knowledge sharing practices. Ref. 17 studied absorptive capacity from an innovation perspective, while Ref. 18 explored entrepreneurship in relation to absorptive capacity. There has also been an extensive debate on the development of absorptive capacity inside the organisation. Researchers ${ }^{19-21}$ have suggested different strategies and methods to absorb external knowledge and have critically evaluated the internal knowledge processing activities. This emerging construct has been discussed at macro level which has been understood at strategic level only, whereas, some studies, such as that by Ref. 22, have discussed human involvement in developing absorptive capacity.

Ref. 22 suggested that absorptive capacity may be enhanced by internal information systems, if managed effectively; they argued that information shared by managers across a company may help employees absorb knowledge more easily and in turn enhance absorptive capacity. Ref. 16 studied various methods for enhancing absorptive capacity through human resource practices and suggested that knowledge transfer may be effectively conducted by taking into account an employee's ability and their motivation to process new knowledge; they further suggested that training employees may have a positive impact in the development of absorptive capacity and discussed that incentive systems for employees, performance based promotion and internal communications have significant impact on absorptive capacity generation and knowledge based activities. The work of Ref. 23 studied absorptive capacity from the perspective of network ties of employees in an organisation. Overall, however, absorptive capacity has been studied in different 
antecedents, but not in great depth at macro level. This study aims to extend this focus by analysing the critical success factors which contribute to the development of absorptive capacity in knowledge intensive environments, taking into account the views of employees and managers operating together in the Pakistani pharmaceutical industry.

\subsection{Knowledge Management}

Knowledge Management began its evolution some three decades ago, but till now has had no agreed universal definition; rather it has been explored from different contexts and perspectives, such as that proposed by Ref. 24 who defined $\mathrm{KM}$ as being the process of capturing, sharing and using knowledge in different contexts from available resources. However, three important aspects of $\mathrm{KM}$ is integration, sharing and access across departments and these have been reported on in literature extensively. ${ }^{25-27}$

Knowledge integration, being an important aspect of knowledge absorption, is practiced in many ways and depends upon the nature of each company. In either form, whether it be formal integration or informal, through managing the knowledge holders where knowledge is possessed by the employees, the process adopted is typically the same and has been highlighted by Ref. 28 through their knowledge management model.

Knowledge sharing is one of the most important factors in the knowledge absorption process, which takes place inside the organisation. It is not a concrete process nor a commodity, which can be transferred easily, but rather is the communication of knowledge explicitly shared between two or multiple parties ${ }^{29-31}$; it is still a significant factor for the absorption of knowledge $^{28}$ and can be termed as transferability by Ref. 32.

Knowledge access across departments in an organisation is also considered an important factor for effective knowledge absorption. ${ }^{5,11}$ Ref. 5 argued that knowledge itself is nothing more than a process, but the handling by employees and managers make it useful. Their recognition can be viewed that knowledge does not serve sole purpose, but the handling by senior management, middle managers and lower level employees help greatly in the absorption and enhancement of absorptive capacity.

\section{Methodology}

This study uses a qualitative, action-based research approach to explore the views of employees and managers in relation to the success factors required in the development of $\mathrm{AC}$ inside an organisation and during knowledge absorption across the organisation. It examines the role played by management and employees in both the development of absorptive capacity and the absorption of knowledge. New insights may be explored by using a step-wise inductive approach and in-depth interviews, which are introduced in the following chapters. The steps taken to conduct this study include: 1) Collection of data; 2) Gathering of feedback from employees; 3 ) analysis of data obtained; 4) planning; 5) implementation; and 6) evaluation of results.

The study was conducted in three phases. In phase 1 , the success factors for the development of absorptive capacity were explored. During phase 2, data absorption across the organisation was studied. Finally, in phase 3, the role of senior management, middle managers and employees were studied in the context of both from an internal and external environment point of view.

Participants involved in this study comprised employees from large pharmaceutical companies based in Pakistan, employing more than 500 plus employees. The companies involved are in a continuous process to acquire new knowledge from outside their organisations, as shown in Fig.5., in order to grow in size, survive in their turbulent marketplace and be considered a knowledge intensive company.

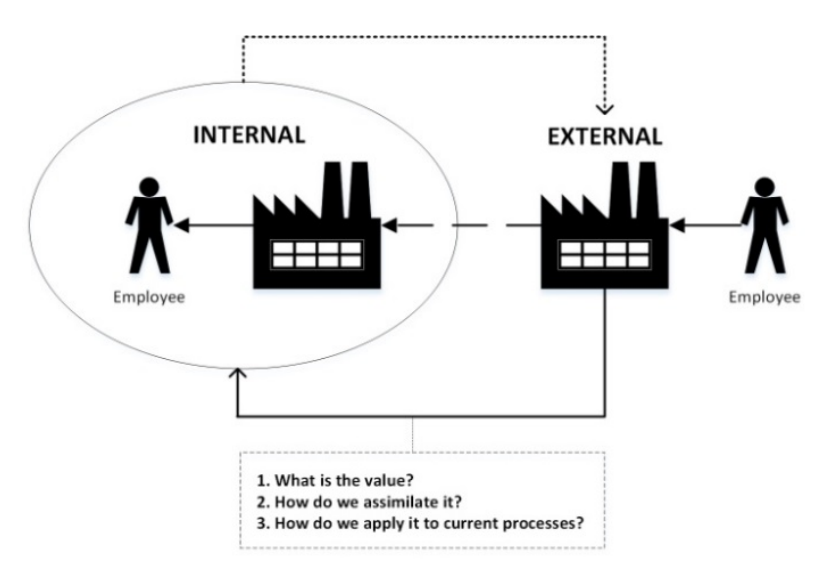

Fig. 5. Continuous Loop of External Knowledge. 
Action Planning Phase...involved the face-to-face interviewing of 18 junior employees, eight mid-level managers and three senior managers. 20 interviews were conducted at the interviewees' place of work, whilst nine were conducted at their home residence, due to personal connections with the authors. These interviews focused on the exploration of the critical success factors for development of absorptive capacity in their respective organisations.

Implementation Phase...involved ten employees, six middle managers and two senior managers whom were interviewed using unstructured questionnaires. 15 of those interviews were conducted at the employees' work places, whilst three preferred to be interviewed off site. This phase focused specifically on the absorption of knowledge and data management processed within the organisation and across departments.

Evaluation Phase....involved the interviewing of 11 employees, 7 middle managers and 5 senior managers; all interviews were conducted face-to-face at the participants' workplace. During this phase, the role of senior management, middle managers and lower level managers were explored and the development of absorptive capacity and data management processes across the organisation was analysed.

\subsection{Research Process}

Our research intended to explore the success factors of organisations attributing to the development of absorptive capacity. Therefore, all interviews lasted between 50-90 minutes in length. The feedback obtained was open and positive. Employees talked openly about the success factors they felt would improve the development of absorptive capacity, data management and knowledge absorption in their companies, especially in relation to specific business processes.

During the action planning stage, employees were interviewed in small groups, with separate face-to-face interviews being conducted with all three levels of managers. During the implementation phase, the remaining employees were interviewed. It was noted that employees were well aware of the KM processes employed within their organisations and, at times, it was felt that junior employees knew better than middle and senior management e.g. employees needed specific flow paths to absorb new knowledge; this requirement was generated by employees, while managers were not clear about the process, which had been internally developed.

During the evaluation phase, interview responses were analysed and reported on. Following the interview analysis, an evaluation report regarding the success factors identified and knowledge absorption across organisation was prepared and the findings are now discussed.

\section{Results}

The adopted research method provided for an in-depth understanding of KM processes in the collaborating companies. Varying success factors were highlighted by employees and managers, while knowledge processes were debated during interview sessions. The role of senior management and managers at all levels were also highlighted by interviewees. Surprisingly, a lot of similarities were found in the responses received during interviews. Following the evaluation of interview data, the following factors for the development of absorptive capacity in organisations were concluded and are now described in the following sub-sections.

\subsection{Success Factors in the Development of Absorptive Capacity}

\subsubsection{Management Related Success Factors}

Senior management support for knowledge management activities in relation to the absorption of new knowledge from outside of the workplace was highlighted as beneficial by the majority of employees and managers during interview; establishment of a network-connected database for improved access to previous references and alignment of new knowledge with incoming knowledge was highlighted by the majority of mid-level managers. Training related to how to improve KM practices, especially in relation to how to use new and emerging technologies, were identified as potentially beneficial to all employees within all collaborating organisations.

\subsubsection{Employee Related Success Factors}

Employee involvement in the development of $\mathrm{KM}$ activities was highlighted as potentially beneficial. Senior management emphasised that employees are the only entity within the organisation whom have to face new knowledge first and, therefore, it is necessary for 
employees to keep themselves abreast with knowledge entering the business at the first possible opportunity.

Employee motivation was highlighted by mid and senior level management as employees with low motivation could affect the KM process, especially when dealing with new knowledge acquired from outside of the organisation. Finally, the technical skills of employees were highlighted by both levels of management. Management commented that their organisations should invest more in new knowledge acquisition systems in order to keep a track of the skill levels of their employees.

\subsubsection{Process Related Success Factors}

Technological bases were commented upon by all parties, stating that business processes should be enhanced to improve the capture, management and sharing of new knowledge acquired into the organisation.

Inter-departmental collaboration should be improved in order to enhance business processes to align existing knowledge with new knowledge; this point was highlighted by employees and managers both as a success factor for acquisition and assimilation of new knowledge.

Refined Research and Development processes and updated process techniques should be improved to assist with continuous process improvement for aligning changes in the organisation due to new knowledge acquired.

\subsection{Absorption of New knowledge across organisation}

The absorption of knowledge was gauged against three important factors as main ingredients of knowledge absorption: 1) knowledge Integration, 2) knowledge sharing and 3) knowledge access.

\subsubsection{Knowledge Integration}

The majority of employees highlighted computer systems and documentation as their main source of knowledge; an integral method, embedded in corporate processes, for improving the usage of these two sources for capturing knowledge is encouraged. However, conflicting points, such as contextual meanings and real meanings were traded off by sense that prevailed in their organisation. At the same time, the retrieval of information was seen as difficult. Concrete data, such as customer requirements and facilitations provided to them, were easy to maintain and integrate into organisational databases.

Some employees, especially mid-level managers, highlighted that the integration of new knowledge was being maintained by the employees themselves in their minds, based on practical experiences (tacit). Any requirement generated regarding new processes is adhered to through team work which is in possession of this knowledge as a whole. The documented approach was not adopted by them as new processes keep on inducting in their routines and documentation was not possible in different contexts at every point. Here, integration of experiences of employees is the key to successful absorptive capacity. However, employees and managers contradicted this view point, as previous knowledge was seen as a strong tool for them to compete in future; well documented knowledge in a logical way was key for defining their future business direction.

The majority of managers showed dissatisfaction towards the existing systems of knowledge integration practices being adopted by their companies. Most employees held the view that their companies always pay special focus on explicit knowledge, but that tacit knowledge integration is ignored. The tacit portion of knowledge is withheld by employees once they switch jobs or even when they switch companies.

Senior employees revealed missing links or communication gaps between employees and management as the main flaw which should be adhered to, to improve knowledge integration. Employees suggested periodic seminars followed by brainstorming sessions for integrating knowledge.

\subsubsection{Knowledge Sharing}

In terms of the sharing of knowledge, employees were asked how knowledge sharing was practiced inside the organisation. The majority of employees shared a common answer: knowledge sharing is practiced at each level, both inside the departments and across departments. On the job sharing of knowledge was observed as common practice. The sharing of experiences specific to problems were also observed as one dimension of knowledge sharing. However, regarding improvements in knowledge sharing practices, the majority of employees suggested that 
interaction sessions be increased and formalised in order to create an effective knowledge base, instead of creating a need-to-know corporate culture. Some employees also reported the introduction of incentive systems for knowledge sharing practices, as it requires extra efforts that are not typically required by their current work contracts. Middle managers highlighted that employees and managers share only common knowledge which is used in daily routines and practices, however, the knowledge critical to business processes was rarely shared by employees especially in normal working hours, as it added to their workloads. In future, it is seen as beneficial to allow employees additional workload hours to capture and share their pre-existing knowledge with colleagues.

\subsubsection{Knowledge Access}

With regard to knowledge access, employees were asked the extent to which they were allowed to access knowledge of the organisation directly or indirectly related to their domains. Responses received show that the majority of employees appeared to have access to knowledge beyond their domains but at the same time specialized knowledge attributing to core knowledge of the company was restricted to specialised employees and, in some cases, could only be accessed on a need-toknow basis. At times, knowledge access only appeared to be available to concerned employees and even if knowledge was accessible to them, it was not useful for them because of their busy schedules and hard tasking by senior managers to junior managers and employees.

\subsection{Role of Managers at each Level}

During this phase, employees, managers and senior management were interviewed in context to their roles played during the development of absorptive capacity and knowledge absorption across their organisation. Table 1 shows the summary of roles played at each level by manager; managers whom had a strong point of view regarding the role played by each level were placed in the category of 'High Role Played' (referred to by 'H'), while managers with mixed remarks, neither high nor low, were assigned the category of 'Moderate Role Played' or ' $\mathrm{M}$ ' and those with a low role were categorised as 'Low Role Played' or 'L'.
Table 1. The role of Managers at different Levels in the Development of Absorptive Capacity and Knowledge Absorption.

\begin{tabular}{l|c|c|c}
\hline \multicolumn{3}{c}{ View Point of Role } \\
\hline & $\begin{array}{c}\text { Junior } \\
\text { Manager }\end{array}$ & $\begin{array}{c}\text { Middle } \\
\text { Manager }\end{array}$ & $\begin{array}{c}\text { Senior } \\
\text { Manager }\end{array}$ \\
\hline $\begin{array}{l}\text { Development } \\
\text { of Absorptive } \\
\text { Capacity }\end{array}$ & $\mathbf{M}$ & $\mathbf{H}$ & $\mathbf{H}$ \\
\hline $\begin{array}{l}\text { Knowledge } \\
\begin{array}{l}\text { Absorption } \\
\text { inside } \\
\text { Organisation }\end{array}\end{array}$ & $\mathbf{H}$ & $\mathbf{M}$ & $\mathbf{L}$ \\
\hline
\end{tabular}

\subsubsection{Senior Management View Point}

Senior managers were seen to have an important role to play in the development of absorptive capacity through junior and middle managers as far as processes and employee related activities were concerned. On average, senior management made middle and junior managers responsible for their own development of absorptive capacity and knowledge absorption activities. However, an important and significant role is played by senior management in context to the management related to absorptive capacity. From a management perspective, principal decision making is carried out at an executive level, but at the same time, senior management play a lesser role in the absorption of new knowledge, as it is required during company processes, so little involvement is required by them.

\subsubsection{Middle Management View Point}

Middle managers were themselves responsible for the development of absorptive capacity and knowledge absorption activities. As they are sandwiched between employees and knowledge process activities, they act as boundary spanners. Although they are directly responsible for the development of absorptive capacity, middle managers had the views that they were less responsible for the absorption of knowledge due to the nature of their assignments and roles in their organisations. Employees were held equally responsible for the development of absorptive capacity as well as knowledge absorption. They viewed senior management as directly responsible for the development of absorptive capacity due to their role and vision both inside and outside of the organisation. They graded senior management low in their abilities to absorb new knowledge. Homogenous views were found in defining 
the roles in context to absorptive capacity development and knowledge absorption.

\subsubsection{Junior Management View Point}

Junior managers held similar views in the defining of roles of different managerial positions, as those of middle managers. Their view point was that middle management was equally responsible for the absorption of knowledge as that of junior managers, because "they are the guide who has to perform every task before us". They reserved their comments related to senior management, but emphasized that every managerial activity, where principal decisions are required, involved senior management and that they are involved in both the development of $\mathrm{AC}$ and knowledge absorption.

\section{Discussion and Analysis}

This study has focused on the development of absorptive capacity in pharmaceutical organisations based in Pakistan. The results of the investigation highlight that the development of absorptive capacity is not only a function that employees and managers must adhere to, but that the involvement of senior management is also equally important. Employee efficiency in the absorbing of new knowledge is dependent upon the involvement of management in addition to the improved alignment of business processes with knowledge management practices; this finding is aligned with the studies of Ref. 11 and 22 . The results of the interviews directly highlight that, without the involvement of management, the absorptive capacity of an employee or organisation may not be processed effectively. Results also highlight that conducting knowledge acquisition and assimilation across departments is one successful antecedent to building strong knowledge bases. The technical infrastructure and R\&D spending of organisations was also highlighted as success factors by employees and managers and are grounded into the original work on absorptive capacity by Ref. 5 .

From an employee perspective, the success factors lay in the domain of managers, whereas, from a manager point of view, employees are seen as the first point of call to define success factors. Senior management held a balanced view in relation to the development of absorptive capacity as they are in the picture of the capabilities of employees and the organisation, plus opportunities available outside the organisation for development of absorptive capacity.

As far as knowledge absorption is concerned, it appears dependent on the three attributes as highlighted by employees and managers at different levels. Results show that knowledge integration is a function of employees experience and personal data bases are used when required. One disadvantage highlighted is that employees carry this knowledge base with them once they switch jobs or leave the company. However, at the same time, it was pointed out by employees that due to time and tough work schedules, they are unable to formulate or develop any system for knowledge integration. Knowledge sharing practices appear to be adhered to by all companies. Knowledge access from outside and inside of the organisation was of prime concern. The successful implementation of any model development of absorptive capacity or knowledge absorption was dependent on employees and managers equally.

\section{Conclusions}

\subsection{Summary of Research Findings}

Absorptive capacity, being the process of absorbing new knowledge form outside the boundaries of an organisation, is dependent upon specific factors in an organisation. Success factors are related to employees and business processes, as well as management. Success factors identified in this study are meshed with different processes and routines found within organisations. The absorption of new knowledge is a function of different antecedents, such as integration and knowledge sharing. Resultantly, the development of absorptive capacity and knowledge absorption is dependent upon human capital.

\subsection{Future Research Direction}

This study was carried out in a knowledge intensive environment with pharmaceutical companies based in Pakistan. The results of this study may be different to that of other industries and could be compared with similar studies in future. Moreover, limited participants were selected for this study and the results may not be the generalised view of other organisations operating in knowledge intensive environments.

The success factors suggested by participants has its own importance, but it is recommended that an order of 
priority of each success factor is developed and should be adhered to in different studies; a further study and analysis from different perspectives of an organisation would improve the current state of research relating to absorptive capacity. Diverse participants with experience in different fields and with different educational backgrounds may be incorporated into the study to explore absorptive capacity further.

\section{Acknowledgements}

The authors of this paper would like to thank all employees based within the collaborating companies for providing valuable insights into current work practices who contributed to this research.

\section{References}

1. I. Nonaka, 'A Dynamic Theory of Organizational Knowledge Creation', Organization Science, Vol. 5, no. 1, 1994 pp. 14-137.

2. M. Rafique, M.T. Nawaz, R.D. Evans and M. Agha, Analysing Success Factors in the Development of Absorptive Capacity in Pharmaceutical Organisations based in Pakistan, in Proc. International Conference on Business Administration, (Dubai, United Arab Emirates, 2015), pp. 235-239.

3. R.D. Evans, J.X. Gao, N. Martin and C. Simmonds, Using Web 2.0-Based Groupware to facilitate Collaborative Design in Engineering Education Scheme Projects, in Proc. International Conference on Interactive Collaborative Learning, (Dubai, United Arab Emirates, 2014) pp. 397-402.

4. V. Janev, A. Dokic, M. Minic and S. Vranes, S, 'Knowledge management in the HR sector of $R \& D$ organizations', in Proc. International Conference on Automation and Information, (Bucharest, Romania, 2008), pp. 315-321.

5. W.M. Cohen and D. Levinthal, 'Absorptive Capacity: A New Perspective on Learning and Innovation', Administrative Science Quarterly, Vol. 35, no. 1, 1990 pp. 128-152.

6. J.D. Teece, G. Pisano and A. Shuen, 'Dynamic Capabilities and Strategic Management', Journal of Strategic Management, Vol. 18, no. 7, 1997 pp. 509-533.

7. S. Sankaran, J. Xu and G. Sankaran, 'Knowledge Sharing in Doctoral Research', The International Technology Management Review, Vol. 1, no. 1, 2007 pp. 34-43.

8. J. Xu and M. Quaddus, 'Exploring the Role of Size in Use Behaviour of Knowledge Management System: An Australian Study', The International Technology Management Review, Vol. 3, no. 1, 2013 pp. 60-70.
9. A.A. Alawneh, E. Hattab and W. Al-Ahmad, 'An Extended Knowledge Management Framework During the Software Development Life Cycle', The International Technology Management Review, Vol. 1, no. 2, 2008 pp. 43-62.

10. M. Sarma and T. Matheus, 'Knowledge Creation in Virtual Communities - Exploring Practices in Open Source Software Hacker Communities', The International Technology Management Review, Vol. 5, no. 2, 2015 pp. 94-104.

11. S.A. Zahra and G. George, 'Absorptive Capacity: A Review, Reconceptualization, and Extension', The Academy of Management Review, Vol. 27, no. 2, 2002 pp. 185-203.

12. J.J.P. Jansen, F.A.J. Van Den Bosch and H.W. Volberda, 'Managing Potential and Realized Absorptive Capacity: How do Organizational Antecedents Matter?', Academy of Management Journal, Vol. 48, no. 6, 2005 pp. 9991015.

13. G. Todorova and B. Durisin, 'Absorptive Capacity: Valuing a Reconceptualization', The Academy of Management Review, Vol. 32, no. 3, 2007 pp. 774-786.

14. P.J. Lane and M. Lubatkin, 'Relative absorptive capacity and interorganizational learning', Strategic Management Journal, Vol. 19, no. 5, 1998 pp. 461-477.

15. P.J. Lane, J.E. Salk and M.A. Lyles, 'Absorptive capacity, learning, and performance in international joint ventures', Strategic Management Journal, Vol. 22, no. 12, 2001 pp. 1139-1161.

16. D. Minbaeva, T. Pedersen, I. Björkman, C.F. Fey and H.J. Park, 'MNC knowledge transfer, subsidiary absorptive capacity, and HRM', Journal of International Business Studies, Vol. 34, no. 6, 2003 pp. 586-599.

17. Z. Su, D. Ahlstrom, J. Li and D. Cheng, 'Knowledge creation capability, absorptive capacity, and product innovativeness', R\&D Management, Vol. 43, no. 5, 2013 pp. 473-485.

18. V.J. García-Moralesa, M.T. Bolívar-Ramosa and R. Martín-Rojasb, 'Technological variables and absorptive capacity's influence on performance through corporate entrepreneurship', Journal of Business Research, Vol. 67, no. 7, 2014 pp. $1468-1477$

19. R. Evans, J. Gao, O. Owodunni, S. Shah, S. Mahdikhah, M. Messaadia and D. Baudry, A Framework for Improving the Sharing of Manufacturing Knowledge through Micro-Blogging, in Proc. Advances in Production Management Systems. Innovative and Knowledge-Based Production Management in a GlobalLocal World, (Ajaccio, France, 2014) pp. 19-26.

20. R.D. Evans, J.X. Gao, S. Woodhead, N. Martin and C. Simmonds, An Investigation into Collaboration and Knowledge Managementduring Product Development in the Aerospace and Defence Industry, in Proc. International Conference on Knowledge Management and Information Sharing, (Barcelona, Spain, 2012) pp. 113-118. 
21. B.A. Piorkowski, J.X. Gao, R.D. Evans and N. Martin, 'A dynamic knowledge management framework for the high value manufacturing industry', International Journal of Production Research, Vol. 51, no. 7, 2012 pp. 2176-2185.

22. M. Lenox and A. King, 'Prospects for developing absorptive capacity through internal information provision', Strategic Management Journal, Vol. 25, no. 4, 2004 pp. 331-345.

23. N. Khachlouf, B.V. Quélin and R. Soparnot, 'Network ties and absorptive capacity for learning and decisionmaking', Journal of Decision Systems, Vol. 23, no. 1, 2014 pp. 4-23.

24. T.H. Davenport, 'Saving IT's Soul: Human-Centered Information Management', Harvard Business Review, Vol. 72, no. 2, 1994 pp. 119-131.

25. C.W. Choo and N. Bontis, The Strategic Management of Intellectual Capital and Organizational Knowledge (Oxford University Press, United Kingdom, 2002).

26. G.D. Bhatt, 'Knowledge Management in Organizations: Examining the Interaction between Technologies, Techniques, and People', Journal of Knowledge Management, Vol. 5, no. 1, 2001 pp. 68-75.
27. M. Alavi and D.E. Leidner, 'Review: Knowledge Management and Knowledge Management Systems: Conceptual Foundations and Research Issues', Journal of Management Information Systems (MIS Quarterly), Vol. 25, no. 1, 2001 pp. 107-136.

28. I. Nonaka and H. Takeuchi, The Knowledge-Creating Company (Oxford University Press, USA, 1995).

29. G.P. Huber, 'Organizational Learning: The Contributing Processes and the Literatures', Organization Science, Vol. 2, no. 1, 1991 pp. 88-115.

30. K.M. Nelson and J.G. Cooprider, 'The Contribution of Shared Knowledge to IS Group Performance', MIS Quarterly, 1996 pp. 409-432.

31. R. Bologa and A.R. Lupu, Accelerating the Sharing of Knowledge in Order to Speed Up the Process of Enlarging Software Development Teams - A Practical Example, in Proc. International Conference on Artificial Intelligence, Knowledge Engineering and Data Bases, (Corfu Island, Greece, 2007), pp. 90-95.

32. R.M. Grant, 'Toward a knowledge-based theory of the firm', StrategicManagement Journal - Special Issue, Vol. 17, Special Issue, 1996 pp. 109-122. 